Kansas State University Libraries

New Prairie Press

\title{
RANDOM MODELS WITH DIRECT AND COMPETITION GENETIC EFFECTS
}

L. , D. Van Vleck

J. P. Cassady

Follow this and additional works at: https://newprairiepress.org/agstatconference

Part of the Agriculture Commons, and the Applied Statistics Commons

\section{(c) (1) $\Theta(9$}

This work is licensed under a Creative Commons Attribution-Noncommercial-No Derivative Works 4.0 License.

\section{Recommended Citation}

Van Vleck, L. , D. and Cassady, J. P. (2004). "RANDOM MODELS WITH DIRECT AND COMPETITION GENETIC EFFECTS," Conference on Applied Statistics in Agriculture. https://doi.org/10.4148/ 2475-7772.1149

This is brought to you for free and open access by the Conferences at New Prairie Press. It has been accepted for inclusion in Conference on Applied Statistics in Agriculture by an authorized administrator of New Prairie Press. For more information, please contact cads@k-state.edu. 


\title{
RANDOM MODELS WITH DIRECT AND COMPETITION GENETIC EFFECTS
}

\author{
L. D. Van Vleck ${ }^{1}$, and J. P. Cassady ${ }^{2}$ \\ ${ }^{1}$ USDA, ARS, USMARC, Lincoln, NE 68583-0908 and ${ }^{2}$ North Carolina State University, \\ Raleigh, NC
}

\begin{abstract}
Livestock producers often select for animals which are genetically superior for yield. Competition among animals in the same pen may affect yield of pen mates. If competitiveness has a genetic component, selection should be for direct genetic effects for yield and for genetic effects of competitiveness on yield of penmates (Muir and Schinkel, 2002). This simulation study examined estimates of variance components from models which ignored competition effects. A population structure of 642 related animals was created. Random effects were residual and pen effects and direct and competition genetic values with genetic correlation. Conclusions, based on 400 replications for 16 different sets of variance parameters, were that competition effects, if ignored, may inflate estimates of pen variance and of direct genetic variance and that ignoring pen effects may increase estimates of the genetic correlation and both genetic variances. Key words: Associative Effects, Genetic Correlation, REML
\end{abstract}

\section{Introduction}

Competition or associative effects as introduced by Muir and Schinkel (2002) may affect performance of other animals in the same pen. Such effects may have a genetic component just as performance is attributed in part to genetic effects of an animal. Thus two genetic effects of each animal may contribute to the phenotypes for performance of animals in a pen. The competition effects of the competitors are imbedded in the phenotype of the animal with the measured performance. Animal breeders have, for many years, dealt with another imbedded trait - the phenotype of the mother for mothering ability for a trait such as weaning weight in beef cattle which may include production of milk for her progeny (e.g., Willham, 1963). The typical jargon common to statistical packages used by animal breeders is to call this a "second" animal effect. The following equations show how the maternal phenotype is imbedded in the direct phenotype of a calf for weaning weight. $\mathrm{P}$ (calf) is the measurement of weaning weight of the calf. G(calf) and E(calf) are the traditional additive genetic and random environmental factors which influence weaning weight of the calf. $\mathrm{MG}(\mathrm{dam}), \mathrm{ME}(\mathrm{dam})$, and $\mathrm{TE}(\mathrm{dam})$ are the maternal additive genetic and maternal permanent environmental effects of the mother on growth of the calf and a maternal temporary environmental effect. The maternal effects are part of $\mathrm{E}$ (calf) so the simple traditional model can be expanded. $\mathrm{E}^{*}$ (calf) is the remainder of $\mathrm{E}$ (calf) that is not associated with the maternal effects. Because $\mathrm{TE}(\mathrm{dam})$ and $\mathrm{E}^{*}$ (calf) cannot be separated, they are combined into $\mathrm{E}^{* *}$. The phenotypic variance $\mathrm{V}(\mathrm{P})$ can be partitioned similarly but may contain a non-zero covariance between the direct genetic value of the calf and the maternal genetic value of its dam because they are related. 


$$
\begin{aligned}
& P(\text { calf })=\text { Fixed effects }+\mathrm{G}(\text { calf })+\mathrm{E}(\text { calf }) \text { with } \\
& \mathrm{E}(\text { calf })=\mathrm{MG}(\text { dam })+\mathrm{ME}(\text { dam })+\mathrm{TE}(\text { dam })+\mathrm{E}^{*}(\text { calf }) \\
& \mathrm{P}(\text { calf })=\text { Fixed effects }+\mathrm{G}(\text { calf })+\mathrm{MG}(\text { dam })+\mathrm{ME}(\text { dam })+\mathrm{E}^{* *}
\end{aligned}
$$

The calf is related to its dam by $1 / 2$. Thus,

$$
\operatorname{COV}[\mathrm{G}(\text { calf }), \operatorname{MG}(\text { dam })]=(1 / 2) \sigma_{\mathrm{GM}} \text { and }
$$$$
\mathrm{V}(\mathrm{P})=\sigma_{\mathrm{G}}^{2}+\sigma_{\mathrm{M}}^{2}+2(1 / 2) \sigma_{\mathrm{GM}}+\sigma_{\mathrm{ME}}^{2}+\sigma_{\mathrm{E}}^{2} * * \text { where }
$$

$\sigma_{\mathrm{G}}^{2}$ is the direct additive genetic variance,

$\sigma_{M}^{2}$ is the maternal additive genetic variance,

$\sigma_{\mathrm{GM}}$ is the direct-maternal additive genetic covariance,

$\sigma_{\mathrm{ME}}^{2}$ is the maternal permanent environmental variance, and

$\sigma_{\mathrm{E}}^{2} * *$ is the residual variance.

The environmental or residual terms for the direct and maternal traits are combined in the phenotype which contains the imbedded maternal trait. Note that the phenotypic variance includes a covariance between the direct genetic effect for the calf and the maternal genetic effect of its mother. Although in the expectation of the square of the model, there are two covariance terms, the final coefficient is one because the mother with the maternal genetic effect and her progeny with the direct genetic effect are related by one-half.

A competition effect is also an imbedded trait. The following equations for three pen mates can be generalized to any number of pen mates (competitors) but three will be enough to describe the basic principles.

$$
\begin{aligned}
& \mathrm{P}(\text { pig } 1)=\text { Fixed effects }+\mathrm{G}(\text { pig } 1)+\mathrm{E}(\text { pig } 1) \text {. With } 2 \text { competitors } \\
& \mathrm{E}(\text { pig } 1)=\mathrm{C}(\text { pig } 2)+\mathrm{CE}(\text { pig } 2)+\mathrm{C}(\text { pig } 3)+\mathrm{CE}(\text { pig } 3)+\mathrm{E}^{*}(\text { pig } 1) \\
& \mathrm{P}(\text { pig } 1)=\text { Fixed effects }+\mathrm{G}(\text { pig } 1)+\mathrm{C}(\text { pig } 2)+\mathrm{C}(\text { pig } 3)+\mathrm{E}^{* *}(1) \\
& \mathrm{P}(\text { pig }) \\
& \mathrm{P}(\text { pig })=\text { Fixed })=\text { Fixed effects }+\mathrm{G}(\text { pig } 2)+\mathrm{C}(\text { pig } 1)+\mathrm{C}(\text { pig } 3)+\mathrm{E}^{* *}(2)
\end{aligned}
$$

As with the maternal effects model, random environmental contributions (CE) to an animal's competitiveness are combined with direct residual effect of the animal with the measured record. In the last 3 equations, the $C$ terms are additive genetic competition effects.

As with the direct-maternal effects model, the competition effects of an animal's competitors are part of the environmental effect for the performance of the measured animal. With competition effects, there can be more than one imbedded competition phenotype. The combined residual term in the model for the measured trait contains the direct environmental effect of the animal as well as the competition environmental effects of its competitors. The 
animal with a measured phenotype will also have its competition phenotype imbedded in the measured phenotypes of its pen mates.

What should be noted is that with the competition model:

1) there may be more than one, "second" animal effect,

2) the competitors may or may not be related to the animal with a record,

3) the "second" animals, may or may not be related,

4) $\mathrm{G}$ (pig 1) and C(pig 1) may have an additive genetic covariance (between an animal's direct and competition additive genetic effects), and

5) the phenotypic variance will depend on genetic covariances between direct and competition effects of relatives, relationships among competitors, and number of competitors.

The phenotypic variance can become complicated. With the direct-maternal effects model, only two animals were involved in the covariance term in the phenotypic variance as one animal contributed to the direct genetic value and its mother to the maternal genetic value. As illustrated in the following equations with one and two competitors, the phenotypic variance will depend on the number of competitors and the genetic relationships among the competitors in the same pen.

With one competitor $(j)$ and $\mathbf{y}_{\mathrm{i}}$, the measurement on animal $\mathrm{i}$ :

$$
\mathrm{V}\left(\mathrm{y}_{\mathrm{i}}\right)=\sigma_{\mathrm{G}}^{2}+\sigma_{\mathrm{C}}^{2}+2\left(\mathrm{a}_{\mathrm{ij}}\right) \sigma_{\mathrm{GC}}+\sigma_{\mathrm{E}}^{2}
$$

where $a_{i j}$ is the numerator relationship between animals $i$ and $j, \sigma_{G}^{2}$ is the direct additive genetic variance, $\sigma_{\mathrm{C}}^{2}$ is the competition additive genetic variance, $\sigma_{\mathrm{GC}}$ is the covariance between direct and competition additive genetic values of an animal and $\sigma_{\mathrm{E}}^{2}$ is the remaining residual variance.

With two competitors $(\mathrm{j}$ and $\mathrm{k})$

$$
\mathrm{V}\left(\mathrm{y}_{\mathrm{i}}\right)=\sigma_{\mathrm{G}}^{2}+2\left(1+\mathrm{a}_{\mathrm{jk}}\right) \sigma_{\mathrm{C}}^{2}+2\left(\mathrm{a}_{\mathrm{ij}}+\mathrm{a}_{\mathrm{ik}}\right) \sigma_{\mathrm{GC}}+\sigma_{\mathrm{E}}^{2}
$$

If the competitors are full sibs;

$$
\left(a_{j k}=a_{i j}=a_{i k}=0.50\right) \text {. }
$$

The inverse of the numerator relationship matrix (Henderson, 1975b, 1976) and the mixed model equations for the individual animal model allowed partitioning of the phenotypic variance for the direct-maternal effects model into direct genetic variance, maternal genetic variance, direct-maternal genetic covariance, and residual variance.

When one of us called the other to ask if the MTDFREML program could be modified to partition direct and competition genetic variances, the answer was a cautious, yes. The modifications were made and seemed successful in assigning the proper coefficients to the 
augmented coefficient matrix (Henderson, 1977) and functions of the records to the right hand side vector of the mixed model equations so that more than one "second" animal effect would be accommodated. As no other program was then available for checking, a set of simulated data was analyzed with one replicate. The solutions resembled the variance parameters put into the simulation although one, or even thousands, of simulations would not prove that the REML algorithm could recover the variance parameters in general (although thousands would be more comforting than a single replicate). In addition, with real data, a pen effect would also be contained in the jumble of direct and competition effects included in the imbedded competition effects model. What is likely to happen with real data is that either or both competition and pen effects might be ignored. Therefore, in addition to doing enough analyses to be comfortable that the REML algorithm could untangle direct and competition and pen effects, a simulation study was done to determine the effect on other variance components when pen effects were ignored, when competition genetic effects were ignored, and when the direct-competition genetic covariance was ignored. In addition, what happens when pen effects, simulated as random effects, are considered to be fixed effects in the REML analysis was investigated.

\section{Methods}

The simulation was for a relatively typical small experiment with two generations of records with no selection. An initial six unselected and unrelated boars were mated to five unselected and unrelated sows to produce in the first generation 30 litters of 10 pigs each. To produce generation two, one female was chosen randomly from each of the 30 litters of generation one. Each of six additional unrelated foundation boars was mated to 5 of those 30 females to produce a total of 30 litters of 10 pigs each in generation two.

The pigs with measurements would be related as full sibs, as paternal half sibs, and as maternal half sibs with some less close relationships across generations one and two. Within each generation, 6 pigs were assigned randomly to each of 50 pens.

In total: 1) $6+6+30+300+300=642$ animals were in the genetic relationship matrix

2) 600 pigs had records in

3) 100 pens (50 each generation)

For the simulation without selection:

1) correlated direct and competition genetic effects $\left(\mathbf{G}_{i}\right.$ and $\left.\mathbf{C}_{i}\right)$ were needed for each of the 642 animals with numerator relationships corresponding to the mating plan,

2) a random residual effect $\left(\mathbf{E}_{i}\right)$ was needed for each of the 600 animals with records, and

3) a random pen effect $\left(\mathbf{P}_{\mathrm{j}}\right)$ was needed for each of the 100 pens.

The genetic relationship matrix, $\mathbf{A}_{+}$, for this design is fixed by the mating structure and is effectively the same for each replication and can be used to simulate the direct and competition genetic values for the 642 animals in the pedigree file. An easy way to calculate $\mathbf{A}_{+}$was to use 
the MTDFNRM program in the MTDFREML (Boldman et al., 1995) package to compute $\mathbf{A}_{+}^{-1}$ with the Henderson-Quaas rules (Henderson, 1976; Quaas, 1976) $\left(\mathbf{A}_{+}^{-1}\right.$ is typically needed in the mixed model coefficient matrix for an animal model as described later.) Then a subroutine was used to invert $\mathbf{A}_{+}^{-1}$ to obtain $\mathbf{A}_{+}$. Then, as will be described, the necessary Choleski factor of $\mathbf{A}_{+}$ was obtained, $\mathbf{L}_{\mathrm{A}}$ (Van Vleck, 1994). For all replicates, only the initial $\mathbf{L}_{\mathrm{A}}$ will be needed.

To build in the genetic covariance and direct and maternal genetic variances, the Choleski factor, $\mathbf{L}_{\mathrm{V}}$, was obtained for

$$
\mathbf{G}_{\mathrm{O}}=\left(\begin{array}{cc}
\sigma_{\mathrm{G}}^{2} & \sigma_{\mathrm{GC}} \\
\sigma_{\mathrm{GC}} & \sigma_{\mathrm{C}}^{2}
\end{array}\right) .
$$

For each set of genetic variance parameters,

$$
\mathbf{L}_{\mathrm{A}} \mathbf{q} \mathbf{L}_{\mathrm{V}} \text { was needed where } \mathrm{q} \text { is the direct product operator. }
$$

When the set of variance parameters was changed, a new $\mathrm{L}_{\mathrm{V}}$ was needed but not a new $\mathrm{L}_{\mathrm{A}}$.

To simulate the paired direct and competition genetic effects $\left(\mathrm{G}_{\mathrm{i}}\right.$ and $\left.\mathrm{C}_{\mathrm{i}}\right)$ for each animal $\mathrm{i}$, a vector, $v$, of pseudo random normal $(0,1)$ variables was generated of length $2 \times 642$. Then

$\left(\mathbf{L}_{\mathrm{A}} \mathrm{q} \mathbf{L}_{\mathrm{V}}\right) \mathbf{v}$ produced the vector of $2 \times 642$ genetic values: $\left(\mathrm{G}_{1}, \mathrm{C}_{1}, \ldots \mathrm{G}_{642} \mathrm{C}_{642}\right)^{\prime}$.

Note that the variance-covariance matrix for $\mathrm{v}$ is $\mathbf{V}(\mathbf{v})=\mathrm{I}$, then

$$
\begin{aligned}
\mathbf{V}\left[\left(\mathbf{L}_{\mathrm{A}} \mathbf{q} \mathbf{L}_{\mathrm{V}}\right) \mathbf{v}\right] & =\left(\mathbf{L}_{\mathrm{A}} \mathbf{q} \mathbf{L}_{\mathrm{V}}\right) \mathbf{V}(\mathbf{v})\left(\mathbf{L}_{\mathrm{A}} \mathbf{q} \mathbf{L}_{\mathrm{V}}\right)^{\prime} \\
& =\left(\mathbf{L}_{\mathrm{A}} \mathbf{q} \mathbf{L}_{\mathrm{V}}\right)\left(\mathbf{L}_{\mathrm{A}} \mathbf{q} \mathbf{L}_{\mathrm{V}}\right)^{\prime}=\mathbf{A} \mathbf{q} \mathbf{G}_{\mathrm{o}}
\end{aligned}
$$

which is the variance-covariance matrix for the 642 pairs of direct and competition genetic effects.

For each simulation, 100 pen effects and 600 residual effects were simulated from pseudo random normal variables $\left[\mathrm{v}_{\mathrm{j}}(\mathrm{j}=1, \ldots, 100)\right]$ and $\left[\mathrm{v}_{\mathrm{k}}(\mathrm{k}=1, \ldots, 600)\right]$ as $\sigma_{P \mathrm{P}_{\mathrm{j}}}$ and $\sigma_{\mathrm{E}} \mathrm{V}_{\mathrm{k}}$ where $\sigma_{\mathrm{P}}$ and $\sigma_{\mathrm{E}}$ are the model standard deviations for pen and residual effects.

Table 1 shows the 16 combinations of variance parameters simulated.

The direct genetic and environmental variances $\sigma_{\mathrm{G}}^{2}$ and $\sigma_{\mathrm{E}}^{2}$ were the same for all combinations of variance parameters (16 and 16) but the other variances and the covariance varied; $\sigma_{\mathrm{P}}^{2}$ from relatively large (10) to small (1), to almost, but not quite, zero (0.1); $\sigma_{\mathrm{GC}}$ so that 
the genetic correlation varied between -0.25 and +0.25 with almost zero for small $\sigma_{\mathrm{GC}}$; and $\sigma_{\mathrm{C}}^{2}$ from 1 to 4 (about $2 \%$ to $10 \%$ of phenotypic variance).

For each of the 16 sets of variance parameters, 400 replicates were simulated.

Each replicate was analyzed with eight different statistical models as shown in Table 2. A zero in Table 2 indicates the component was ignored in the model for that analysis. The last three models treated pen effects as fixed even though simulated as random effects (Table 1).

The full model for the simulation and for statistical analyses (Model 1 or Model 6 with pens as fixed effects) is:

$\mathbf{y}=\mathbf{X} \boldsymbol{\beta}+\mathbf{Z}_{+} \mathbf{g}_{+}+\mathbf{W}_{+} \mathbf{c}_{+}+\mathbf{S p}+\mathbf{e}$ where

$\mathbf{g}_{+}$is the augmented vector of direct genetic effects,

$\mathbf{c}_{+}$is the augmented vector of competition genetic effects,

p is the vector of random pen effects (with Model 6 they are assumed to be fixed effects),

e is the vector of random residuals, and

$\mathbf{X}, \mathbf{Z}_{+}, \mathbf{W}_{+}$and $\mathbf{S}$ are incidence matrices which associate effects in $\boldsymbol{\beta}, \mathbf{g}_{+}, \mathbf{c}_{+}$, and $\mathbf{p}$ with $\mathbf{y}$.

The $\mathbf{g}_{+}$and $\mathbf{c}_{+}$vectors are augmented for animals in the pedigree but without records. The corresponding columns of $\mathbf{Z}_{+}$and $\mathbf{W}_{+}$will contain only zeroes for animals without records. This augmentation allows use of the Henderson-Quaas rules for easy calculation of $\mathrm{A}_{+}^{-1}$. Solutions to the equations and estimates of variance components will be the same as when not augmented (Henderson, 1977).

The variance structure with random pen effects is:

$$
\mathbf{v}\left(\begin{array}{c}
\mathbf{g}_{+} \\
\mathbf{c}_{+} \\
\mathbf{p} \\
\mathbf{e}
\end{array}\right)=\left(\begin{array}{cccc}
\mathbf{A}_{+} \sigma_{\mathrm{G}}^{2} & \mathbf{A}_{+}{ }^{\sigma} \mathrm{GC} & 0 & 0 \\
\mathbf{A}_{+}{ }^{\sigma} \mathrm{GC} & \mathbf{A}_{+} \sigma_{\mathrm{C}}^{2} & 0 & 0 \\
0 & 0 & \mathbf{I}_{\mathrm{P}}{ }_{\mathrm{P}}^{2} & 0 \\
0 & 0 & 0 & \mathbf{I}_{\mathrm{e}} \sigma_{\mathrm{E}}^{2}
\end{array}\right)
$$

Let

$$
\begin{aligned}
& \mathbf{G}_{\mathrm{O}}=\left(\begin{array}{cc}
\sigma_{\mathrm{G}}^{2} & \sigma_{\mathrm{GC}} \\
\sigma_{\mathrm{GC}} & \sigma_{\mathrm{C}}^{2}
\end{array}\right) \text { so that } \\
& \mathbf{G}_{0}^{-1} \sigma_{\mathrm{E}}^{2}=\left(\begin{array}{ll}
{ }_{\mathrm{g}} \mathrm{GG} & { }_{\mathrm{g}} \mathrm{GC} \\
{ }_{\mathrm{g}} \mathrm{GC} & { }_{\mathrm{g}} \mathrm{CC}
\end{array}\right) \text { and } \lambda=\sigma_{\mathrm{E}}^{2} / \sigma_{\mathrm{P}}^{2} .
\end{aligned}
$$


The Mixed Model Equations x $\sigma_{\mathrm{E}}^{2}$ (Henderson et al., 1959; Henderson, 1963, 1973, 1975a, 1975b) are:

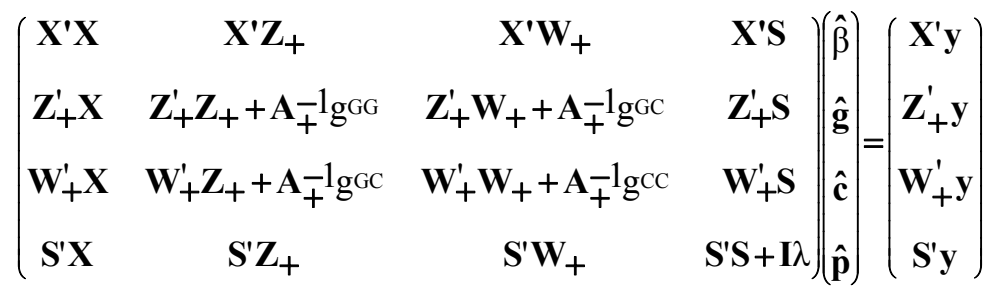

All analyses were with the MTDFREML package which is based on a derivative-free REML algorithm (Boldman et al., 1995).

\section{Results}

Statistical Models 7 and 8 did not produce any surprising results so are ignored here. Tables 3 to 8 show the means of estimates for 400 replicates with statistical models 1 to 6 for variance parameter sets 1 to 6 . Tables of means of estimates for the other 10 parameter sets showed similar patterns so will not be discussed.

The results show that the REML algorithm with the full model and the genetic relationship matrix, estimates of $\sigma_{\mathrm{G}}^{2}, \sigma_{\mathrm{C}}^{2}, \sigma_{\mathrm{GC}}, \sigma_{\mathrm{P}}^{2}$, and $\sigma_{\mathrm{E}}^{2}$ can be partitioned from the total variance.

If the genetic correlation between direct and competition effects $\left(\mathbf{r}_{\mathrm{g}}\right)$, was ignored, estimates of $\sigma_{\mathrm{P}}^{2}$ decreased if $\mathbf{r}_{\mathrm{g}}$ was negative and increased if $\mathbf{r}_{\mathrm{g}}$ was positive.

If both $\mathbf{r}_{\mathrm{g}}$ and $\sigma_{\mathrm{C}}^{2}$ were ignored, then estimates of $\sigma_{\mathrm{P}}^{2}$ increased dramatically if $\mathbf{r}_{\mathrm{g}}$ was negative and increased even more dramatically if $r_{g}$ was positive.

If, on the other hand, $\sigma_{\mathrm{P}}^{2}$ was ignored, then estimates of both $\sigma_{\mathrm{GC}}$ and $\sigma_{\mathrm{C}}^{2}$ increased. The increase was greater with larger $\sigma_{\mathrm{P}}^{2}$ but not to the extent that estimates of $\sigma_{\mathrm{P}}^{2}$ increased when $\sigma_{\mathrm{C}}^{2}$ was ignored.

A rather obvious question is "Why is $\sigma_{\mathrm{P}}^{2}$ (the pen variance) inflated when $\sigma_{\mathrm{C}}^{2}$ and $\sigma_{\mathrm{GC}}$ are ignored?" One partial explanation goes back at least 50 years when statisticians and animal breeders were generally limited to estimates of variance components with one-way classification models. model:

With Henderson's Method One, we were taught that with the intraclass correlation (sire) 
$\sigma_{\mathrm{S}}^{2}=\mathrm{COV}(\mathrm{PHS} 1, \mathrm{PHS} 2)$ where PHS1 and PHS2 were records of any pair of paternal half-sibs (having the same father but different mothers). Thus, $\sigma_{\mathrm{S}}^{2}$ was the covariance between any pair of records in the group. The assumption was that only genes from the sire in common for the pair of paternal half-sibs contribute to the covariance between records of pairs of paternal half-sibs (the sire component of variance).

The competition model, however, is much more complicated.

For one pen (pen effect $=\mathbf{p})$ with 6 pen mates ( 5 competitors), let $\mathbf{y}_{1}$ and $\mathbf{y}_{2}$ be a pair of records from the same pen after adjustment for fixed effects:

$$
\begin{aligned}
& \mathbf{y}_{1}=\mathbf{g}_{1}+\mathbf{c}_{2}+\mathbf{c}_{3}+\mathbf{c}_{4}+\mathbf{c}_{5}+\mathbf{c}_{6}+\mathbf{p}+\mathbf{e}_{1} \\
& \mathbf{y}_{2}=\mathbf{g}_{2}+\mathbf{c}_{1}+\mathbf{c}_{3}+\mathbf{c}_{4}+\mathbf{c}_{5}+\mathbf{c}_{6}+\mathbf{p}+\mathbf{e}_{2}
\end{aligned}
$$

If $\sigma_{\mathrm{C}}^{2}$ and $\sigma_{\mathrm{GC}}$ are ignored in the analysis and all animals are unrelated:

$$
\operatorname{COV}\left(\mathbf{y}_{1}, \mathbf{y}_{2}\right)=4 \sigma_{\mathrm{C}}^{2}+\sigma_{\mathrm{P}}^{2}+2 \sigma_{\mathrm{GC}}
$$

Obviously, more than pen effects are in common between pairs of records in a pen. For example, if variances for Parameter Sets (1 to 4) are substituted into $\operatorname{COV}\left(\mathbf{y}_{1}, \mathbf{y}_{2}\right)$, general agreement can be seen with the estimates of pen variance whether the true pen variance was 10 or only 1 .

$$
\begin{aligned}
& \text { (1): } 4(4)+10+2(-2)=22 \text { vs } \frac{\hat{\sigma}_{\mathrm{P}}^{2}}{25.5} \\
& \text { (2): } 4(4)+10+2(2)=30 \text { vs } 30.6 \\
& \text { (3): } 4(4)+1+2(-2)=13 \text { vs } 16.5 \\
& \text { (4): } 4(4)+1+2(2)=21 \text { vs } 21.1
\end{aligned}
$$

If only $\sigma_{\mathrm{GC}}$ is ignored, then

$$
\operatorname{COV}\left(\mathbf{y}_{1}, \mathbf{y}_{2}\right)=\sigma_{\mathrm{P}}^{2}+2 \sigma_{\mathrm{GC}}
$$

(This time comparison between $\operatorname{COV}\left(\mathbf{y}_{1}, \mathbf{y}_{2}\right)$ and the estimate of pen variance will be with estimates for Parameter Sets (1, 2, 3, 4, 13, and 14).

$$
\begin{array}{rrlrlr}
\text { (1): } & 10+2(-2) & = & 6 & \mathrm{vs} & \frac{\hat{\sigma}_{\mathrm{P}}^{2}}{6.5} \\
\text { (3): } 1+2(-2) & = & -3 \mathrm{vs} & 0.6 \\
\text { (13): } & .1+2(-2) & = & -3.9 \mathrm{vs} & 0.5 \\
\text { (2): } & 10+2(2) & = & 14 & \mathrm{vs} & 13.8 \\
(4): & 1+2(2) & = & 5 & \mathrm{vs} & 3.4 \\
(14): & .1+2(2) & = & 4.1 & \mathrm{vs} & 4.3
\end{array}
$$


Again, this equation explains much of the difference between the true pen variance and estimates when the genetic covariances are ignored. With Parameter Sets (3) and (13), the equation leads to a negative expectation of the variance which is outside the parameter space for a REML estimate although the REML estimates were small. When a positive genetic covariance was ignored, the pen variance was substantially overestimated but was close to what was predicted by the equation that considered the covariance between random pairs of records contributed by the direct-competition genetic covariance. Although the true situation is more complex, the simple expectations based on pairs of animals in the same pen explain much of the difference between estimates of pen variance and true pen variance.

\section{Summary}

1) Relationships among animals with the full model:

a) allowed recovery of $\sigma_{\mathrm{G}}^{2}, \sigma_{\mathrm{C}}^{2}, \sigma_{\mathrm{GC}}, \sigma_{\mathrm{P}}^{2}$, and $\sigma_{\mathrm{E}}^{2}$ for a trait with imbedded competition effects,

b) but with small $\sigma_{\mathrm{P}}^{2}, \sigma_{\mathrm{P}}^{2}$ was consistently overestimated.

2) If competition effects were ignored:

a) $\hat{\sigma}_{\mathrm{P}}^{2}$ was inflated,

b) if the direct-competition genetic correlation was positive, the estimate of the correlation increased, although $\hat{\sigma}_{\mathrm{G}}^{2}$ was affected only a little,

c) if the direct-competition genetic correlation was negative, the estimate of $\sigma_{\mathrm{P}}^{2}$ increased less, but $\hat{\sigma}_{\mathrm{G}}^{2}$ did increase, and

d) obviously, the ignored variances go someplace but not to the residual variance (unless only $\sigma_{\mathrm{G}}^{2}$ and $\sigma_{\mathrm{E}}^{2}$ were estimated).

3) Analysis with the model assuming pen effects were fixed:

a) allowed separation of $\sigma_{\mathrm{G}}^{2}, \sigma_{\mathrm{GC}}, \sigma_{\mathrm{C}}^{2}$, and $\sigma_{\mathrm{E}}^{2}$, and

b) resulted in smaller $\mathrm{SE}$ of estimates of $\sigma_{\mathrm{GC}}$ and $\sigma_{\mathrm{C}}^{2}$ (results not shown here).

4) As a word of caution, estimates for models with competition effects with real data will likely depend on:

a) design of the experiment and corresponding parameters,

b) features of the pen such as shape and feeding space,

c) number of competitors,

d) the method for assigning pigs to pens, and

e) the pedigree structure within and across pens.

5) The next step would be to examine estimates of direct and competition additive genetic values with models containing competition effects. 


\section{Literature Cited}

Boldman, K. G., L. A. Kriese, L. D. Van Vleck, C. P. Van Tassell, and S. D. Kachman. 1995. A Manual for Use of MTDFREML (DRAFT). A set of programs to obtain estimates of variances and covariances. USDA-ARS, Roman L. Hruska U.S. Meat Animal Research Center, Clay Center, NE. (120 pp).

Henderson, C. R. 1963. Selection index and expected genetic advance. In: Statistical Genetics and Plant Breeding. Publication 982, National Academy of Science - National Research Council, Washington, DC, pp 141-163.

Henderson, C. R. 1973. Sire evaluation and genetic trends. In: Proceedings of the Animal Breeding and Genetics Symposium in Honor of Dr. Jay L. Lush. Am. Soc. An. Sci. and Am. Dairy Sci. Assn., Champaign, IL. pp 10-43.

Henderson, C. R. 1975a. Best linear unbiased estimation and prediction under a selection model. Biometrics 31:423-447.

Henderson, C. R. 1975b. Use of all relatives in intraherd prediction of breeding values and real producing abilities. J. Dairy Sci. 58:1910-1916.

Henderson, C. R. 1976. A simple method for computing the inverse of a numerator relationship matrix used in prediction of breeding values. Biometrics 32:69-83.

Henderson, C. R. 1977. Best linear unbiased predictions of breeding values not in the model for records. J. Dairy Sci. 60:783-787.

Henderson, C. R., O. Kempthorne, S. R. Searle, and C. N. von Krosigk. 1959. The estimation of environmental and genetic trends from records subject to culling. Biometrics 15:192-218.

Muir, W. M., and A. Schinkel. 2002. Incorporation of competitive effects in breeding programs to improve productivity and animal well being. In: Editors. Proc. $7^{\text {th }}$ World Cong. on Genetics Appl. to Livestock Prod. CD-ROM communication no 14-07. Montpellier, France, Aug. 19-23, 2002.

Quaas, R. L. 1976. Computing the diagonal elements and inverse of a large numerator relationship matrix. Biometrics 32:949-953.

Van Vleck, L. D. 1994. Algorithms for simulation of animal models with multiple traits and with maternal and non-additive genetic effects. Brazilian J. Genetics 17:53-57.

Willham, R. L. 1963. The covariance between relatives for characters composed of components contributed by related individuals. Biometrics 19:18-27. 
Table 1. Combinations of variance parameters for simulation ${ }^{\mathrm{a}}$

\begin{tabular}{cccccc}
\hline $\begin{array}{c}\text { Parameter } \\
\text { Set }\end{array}$ & $\sigma_{\mathrm{G}}^{2}$ & $\sigma_{\mathrm{GC}}$ & $\sigma_{\mathrm{C}}^{2}$ & $\sigma_{\mathrm{P}}^{2}$ & $\sigma_{\mathrm{E}}^{2}$ \\
\hline 1 & 16 & -2 & 4 & 10 & 16 \\
2 & 16 & 2 & 4 & 10 & 16 \\
3 & 16 & -2 & 4 & 1 & 16 \\
4 & 16 & 2 & 4 & 1 & 16 \\
5 & 16 & -1 & 1 & 10 & 16 \\
6 & 16 & 1 & 1 & 10 & 16 \\
7 & 16 & .1 & 4 & 10 & 16 \\
8 & 16 & .1 & 4 & 1 & 16 \\
9 & 16 & .1 & 1 & 10 & 16 \\
10 & 16 & .1 & 1 & 1 & 16 \\
11 & 16 & -1 & 1 & 1 & 16 \\
12 & 16 & 1 & 1 & 1 & 16 \\
13 & 16 & -2 & 4 & .1 & 16 \\
14 & 16 & 2 & 4 & .1 & 16 \\
15 & 16 & .1 & 4 & .1 & 16 \\
16 & 16 & .1 & 1 & .1 & 16 \\
\hline
\end{tabular}

${ }^{\mathrm{a}} \sigma_{\mathrm{G}}^{2}=$ direct genetic variance, $\sigma_{\mathrm{C}}^{2}=$ competition genetic variance, $\sigma_{\mathrm{GC}}=$ covariance between direct and competition genetic effects, $\sigma_{\mathrm{P}}^{2}=$ variance of pen effects, and $\sigma_{\mathrm{E}}^{2}=$ variance of uncorrelated residual effects.

Table 2. Assumptions for statistical models for analyses ${ }^{\mathrm{a}}$

\begin{tabular}{cccccc}
\hline Model & $\sigma_{\mathrm{G}}^{2}$ & $\sigma_{\mathrm{GC}}$ & $\sigma_{\mathrm{C}}^{2}$ & $\sigma_{\mathrm{P}}^{2}$ & $\sigma_{\mathrm{E}}^{2}$ \\
\hline 1 & $\sqrt{ }$ & $\sqrt{ }$ & $\sqrt{ }$ & $\sqrt{ }$ & $\sqrt{ }$ \\
2 & $\sqrt{ }$ & 0 & $\sqrt{ }$ & $\sqrt{ }$ & $\sqrt{ }$ \\
3 & $\sqrt{ }$ & 0 & 0 & $\sqrt{ }$ & $\sqrt{ }$ \\
4 & $\sqrt{ }$ & $\sqrt{ }$ & $\sqrt{ }$ & 0 & $\sqrt{ }$ \\
5 & $\sqrt{ }$ & 0 & 0 & 0 & $\sqrt{ }$ \\
6 & $\sqrt{ }$ & $\sqrt{ }$ & $\sqrt{ }$ & Fix & $\sqrt{ }$ \\
7 & $\sqrt{ }$ & 0 & $\sqrt{ }$ & Fix & $\sqrt{ }$ \\
8 & $\sqrt{ }$ & 0 & 0 & Fix & $\sqrt{ }$ \\
\hline
\end{tabular}

$\sqrt[a]{\text { indicates included in the analysis, } 0 \text { indicates not included, Fix }}$ indicates the random pen effects were considered to be fixed effects in the analyses. 
Table 3. Means of estimates from 400 replicates with Parameter Set 1 with Analysis Models 1 to 6 compared with true values of the variance parameters.

\begin{tabular}{crrrrr}
\hline \hline Analysis & $\sigma_{\mathrm{G}}^{2}$ & $\sigma_{\mathrm{GC}}$ & $\sigma_{\mathrm{C}}^{2}$ & $\sigma_{\mathrm{P}}^{2}$ & $\sigma_{\mathrm{E}}^{2}$ \\
\hline True & 16.0 & -2.0 & 4.0 & 10.0 & 16.0 \\
1 & 15.9 & -2.1 & 4.0 & 10.0 & 16.0 \\
2 & 17.6 & - & 4.4 & 6.5 & 17.0 \\
3 & 22.6 & - & - & 25.5 & 16.9 \\
4 & 17.4 & 0.1 & 6.5 & - & 16.3 \\
5 & 18.7 & - & - & - & 43.2 \\
6 & 15.3 & -2.3 & 4.2 & Fix & 16.0 \\
\hline
\end{tabular}

Table 4. Means of estimates from 400 replicates with Parameter Set 2 with Analysis Models 1 to 6 compared with true values of the variance parameters.

\begin{tabular}{cccccc}
\hline Analysis & $\sigma_{\mathrm{G}}^{2}$ & $\sigma_{\mathrm{GC}}$ & $\sigma_{\mathrm{C}}^{2}$ & $\sigma_{\mathrm{P}}^{2}$ & $\sigma_{\mathrm{E}}^{2}$ \\
\hline True & 16.0 & 2.0 & 4.0 & 10.0 & 16.0 \\
1 & 15.6 & 1.8 & 3.9 & 10.6 & 16.2 \\
2 & 13.9 & - & 3.5 & 14.0 & 15.5 \\
3 & 16.2 & - & - & 30.6 & 16.2 \\
4 & 18.4 & 4.5 & 6.5 & - & 16.3 \\
5 & 19.8 & - & - & - & 42.8 \\
6 & 16.0 & 2.2 & 4.3 & Fix & 16.1 \\
\hline
\end{tabular}


Table 5. Means of estimates from 400 replicates with Parameter Set 3 with Analysis Models 1 to 6 compared with true values of the variance parameters.

\begin{tabular}{crrrrr}
\hline \hline Analysis & $\sigma_{\mathrm{G}}^{2}$ & $\sigma_{\mathrm{GC}}$ & $\sigma_{\mathrm{C}}^{2}$ & $\sigma_{\mathrm{P}}^{2}$ & $\sigma_{\mathrm{E}}^{2}$ \\
\hline True & 16.0 & -2.0 & 4.0 & 1.0 & 16.0 \\
1 & 16.3 & -2.5 & 3.8 & 2.3 & 15.4 \\
2 & 18.0 & - & 3.5 & 0.6 & 17.1 \\
3 & 22.7 & - & - & 16.5 & 16.9 \\
4 & 16.4 & -2.0 & 4.3 & - & 15.6 \\
5 & 19.2 & - & - & - & 34.2 \\
6 & 16.0 & -2.3 & 4.2 & Fix & 15.5 \\
\hline
\end{tabular}

Table 6. Means of estimates from 400 replicates with Parameter Set 4 with Analysis Models 1 to 6 compared with true values of the variance parameters.

\begin{tabular}{cccccc}
\hline Analysis & $\sigma_{\mathrm{G}}^{2}$ & $\sigma_{\mathrm{GC}}$ & $\sigma_{\mathrm{C}}^{2}$ & $\sigma_{\mathrm{P}}^{2}$ & $\sigma_{\mathrm{E}}^{2}$ \\
\hline True & 16.0 & 2.0 & 4.0 & 1.0 & 16.0 \\
1 & 15.4 & 1.5 & 3.5 & 3.0 & 16.1 \\
2 & 14.3 & - & 3.4 & 4.8 & 15.2 \\
3 & 16.2 & - & - & 21.1 & 16.1 \\
4 & 16.1 & 2.3 & 4.2 & - & 16.2 \\
5 & 19.0 & - & - & - & 34.1 \\
6 & 15.8 & 2.1 & 4.4 & Fix & 16.1 \\
\hline
\end{tabular}


Table 7. Means of estimates from 400 replicates with Parameter Set 5 with Analysis Models 1 to 6 compared with true values of the variance parameters.

\begin{tabular}{crrrrr}
\hline \hline Analysis & $\sigma_{\mathrm{G}}^{2}$ & $\sigma_{\mathrm{GC}}$ & $\sigma_{\mathrm{C}}^{2}$ & $\sigma_{\mathrm{P}}^{2}$ & $\sigma_{\mathrm{E}}^{2}$ \\
\hline True & 16.0 & -1.0 & 1.0 & 10.0 & 16.0 \\
1 & 15.8 & -1.0 & 1.0 & 9.9 & 16.1 \\
2 & 16.9 & - & 1.1 & 8.5 & 16.6 \\
3 & 18.0 & - & - & 13.1 & 16.7 \\
4 & 18.6 & 1.7 & 3.2 & - & 16.6 \\
5 & 16.4 & - & - & - & 30.4 \\
6 & 15.7 & -1.1 & 1.1 & Fix & 16.1 \\
\hline
\end{tabular}

Table 8. Means of estimates from 400 replicates with Parameter Set 6 with Analysis Models 1 to 6 compared with true values of the variance parameters.

\begin{tabular}{cccccc}
\hline \hline Analysis & $\sigma_{\mathrm{G}}^{2}$ & $\sigma_{\mathrm{GC}}$ & $\sigma_{\mathrm{C}}^{2}$ & $\sigma_{\mathrm{P}}^{2}$ & $\sigma_{\mathrm{E}}^{2}$ \\
\hline True & 16.0 & 1.0 & 1.0 & 10.0 & 16.0 \\
1 & 16.0 & 1.1 & 1.1 & 9.8 & 16.0 \\
2 & 14.9 & - & 0.9 & 11.5 & 15.6 \\
3 & 15.5 & - & - & 15.8 & 15.8 \\
4 & 19.9 & 4.0 & 3.1 & - & 16.1 \\
5 & 17.3 & - & - & - & 30.0 \\
6 & 16.0 & 1.1 & 1.1 & Fix & 16.0 \\
\hline
\end{tabular}

